\title{
Cosmetic outcome as rated by patients, doctors, nurses and BCCT.core software assessed over 5 years in a subset of patients in the TARGIT-A Trial
}

Tammy Corica ${ }^{1,2^{*}}$ D, Anna K. Nowak², Christobel M. Saunders², Max K. Bulsara ${ }^{3}$, Mandy Taylor ${ }^{4}$, Norman R. Williams ${ }^{5}$, Mohammed Keshtgar ${ }^{6}$, David J. Joseph ${ }^{2,4}$ and Jayant S. Vaidya ${ }^{7}$

\begin{abstract}
Background: The purpose of this research was to assess agreement between four rating systems of cosmetic outcome measured in a subset of patients with early breast cancer participating in the randomised TARGIT-A trial. TARGIT-A compared risk-adapted single-dose intra-operative radiotherapy (TARGIT-IORT) to whole breast external beam radiotherapy (EBRT).

Methods: Patients, their Radiation Oncologist and Research Nurse completed a subjective cosmetic assessment questionnaire before radiotherapy and annually thereafter for five years. Objective data previously calculated by the validated BCCT.core software which utilizes digital photographs to score symmetry, colour and scar was also used. Agreement was assessed by the Kappa statistic and longitudinal changes were assessed by generalized estimating equations.
\end{abstract}

Results: Overall, an Excellent-Good (EG) cosmetic result was scored more often than a Fair-Poor (FP) result for both treatment groups across all time points, with patients who received TARGIT-IORT scoring EG more often than those who received EBRT however this was statistically significant at Year 5 only. There was modest agreement between the four rating systems with the highest Kappa score being moderate agreement which was between nurse and doctor scores at Year 1 with Kappa $=0.46(p<0.001), 95 \% \mathrm{Cl}(0.24,0.68)$.

Conclusion: Despite similar overall findings between treatment groups and rating systems, the inter-rater agreement was only modest. This suggests that the four rating systems utilized may not necessarily be used interchangeably and it is arguable that for an outcome such as cosmetic appearance, the patient's point of view is the most important.

Trial Registration: TARGIT-A ISRCTN34086741, Registered 21 July 2004, retrospectively registered.

Keywords: BCCT.core, Breast Cancer, Cosmesis, Cosmetic Rating Systems, External Beam Radiotherapy, Targeted Intraoperative Radiotherapy, TARGIT-IORT

\footnotetext{
* Correspondence: Tammy.Corica@health.wa.gov.au

${ }^{1}$ Radiation Oncology Clinical Trials and Research Unit, Comprehensive Cancer

Centre, Sir Charles Gairdner Hospital, Nedlands, WA 6009, Australia

${ }^{2}$ Medical School, University of Western Australia, Nedlands, WA 6009,

Australia

Full list of author information is available at the end of the article
} 


\section{Background}

Standard adjuvant treatment for women undergoing breast conserving surgery (BCS) is whole breast external beam radiotherapy (EBRT) delivered in 15-35 daily fractions over a period of 3-7 weeks [1-6]. Several countries have already adopted the use of Targeted IntraOperative Radiotherapy utilising the Intrabeam device (TARGIT-IORT) as a form of partial breast irradiation for suitable women, which allows the delivery of radiation directly to the tissues at the site of the primary tumour in a single session at the time of wide local excision (WLE) or shortly afterwards. When compared to EBRT in the TARGIT-A Trial, TARGIT-IORT was found to be non-inferior in terms of local recurrence with no difference in breast-cancer survival and a small but significant improvement in non-breast-cancer survival favoring TARGIT-IORT. Unlike TARGIT-IORT delivered prepathology (during WLE), non-inferiority could not be established for postpathology TARGITIORT (separate to WLE), but the difference in local recurrence was not statistically significant [7]. Within a sub-group of the TARGIT-A trial $(n=342)$, cosmetic outcome based on objective measurements was found to be better with TARGIT IORT, particularly in the first year after surgery [8]. Previous analysis of the present dataset has shown similar cosmetic outcomes when comparing TARGIT-IORT to EBRT, but better breastrelated quality of life, both as scored by patients [9].

Over time, a variety of methods to measure cosmetic outcome have been explored due to the importance of such secondary outcomes when assessing the acceptability of new treatments with similar efficacy to standard care. In 1979 Harris described a subjective assessment utilising a four point scale comparing the treated breast to the untreated breast. Objective measurements assessing breast retraction (BRA) were described by Pezner in 1985; then further developed by Christie in 2005 with the use of photographic assessment; then in 2007 by Fitzal with the Breast Analysing Tool (BAT) and by Cardoso with the development and validation of the BCCT.core software (Breast Cancer Conservative Treatment.Cosmetic results) [10-17]. Limited reproducibility of subjective results led to the investigation of objective measurements, however it has been argued that patientassessed cosmetic outcome is the most important as it is the woman who must live with her cosmetic outcome, despite patients tending to score themselves more positively than their health care providers [11, 13, 18-20].

In the absence of a gold standard approach for assessing cosmesis, four existing and reasonably practical methods were utilised to compare cosmetic outcome between TARGIT-IORT and EBRT; a) subjective patient self-assessment, b) live subjective assessment by a nurse and c) a doctor (Radiation Oncologist), and d) digital photographic assessment to provide an objective measure of breast retraction, colour and scar; scoring for each assessment was based on the Harris scale [10]. This current report expands on previously reported subjective (patient self-assessment) [9] and objective (BCCT.core) outcomes [8] by focusing on agreement on cosmetic outcome between the different rating systems.

\section{Methods}

\section{Patients and Treatment}

As previously reported, 3451 patients from 33 centres in 11 countries participated in the TARGIT-A trial between 2000 and 2012 [7, 9]. Patients with early breast cancer suitable for breast conserving surgery were randomized to receive either a single dose of TARGIT-IORT $(50 \mathrm{kV}$ X-rays with INTRABEAM ${ }^{(\mathrm{rm})}$ Carl Zeiss, Oberkochen Germany) or conventional 3-7 weeks' EBRT. TARGITIORT patients with unfavourable pathology also received EBRT in $\sim 15 \%$ of cases however these were excluded from this analysis. TARGIT-IORT dose to $1 \mathrm{~cm}$ was 5-6Gy (16-33Gy at applicator surface) and EBRT was conventional 3-dimensional conformal radiotherapy (4550.4 Gy in 15-28 fractions) [21].

This cosmesis sub-study includes 126 patients from 3 hospitals in Western Australia randomized predominantly in the postpathology setting. Relevant ethics approvals were obtained and all participants provided written informed consent.

Eligibility for Australian patients randomized postpathology was stricter than the main trial; unifocal invasive ductal $<2 \mathrm{~cm}$ tumours, node negative, hormone receptor positive, limited DCIS and no lymphovascular invasion. Fourteen EBRT and 4 IORT patients in this analysis were randomised before their WLE (prepathology stratification) where these stricter criteria did not apply hence some deviations are shown in Table 1.

\section{Instruments and evaluations \\ Cosmesis Harris Scale}

Patients completed a self-reported cosmetic assessment at baseline (before radiotherapy) and annually thereafter for five years as previously reported [9]. At the same time points, a Radiation Oncologist and a Research Nurse independently completed the same cosmetic assessment for each patient, blinded to other rater scores. Doctor and nurse raters were also involved in patient care and were not blinded to treatment allocation. At the same timepoints, digital photographs were taken of the unclothed torso from neck to navel, frontal view, with the patient standing, a method used by others [12, 22]. All baseline measurements were taken before radiotherapy, the majority being after WLE, except $3 \%$ in the TARGIT-IORT group and $18 \%$ in the EBRT group that were taken before WLE (where patients were randomised before their WLE 
Table 1 Baseline patient characteristics by treatment

\begin{tabular}{|c|c|c|}
\hline $\begin{array}{l}\text { Patient, treatment and tumour } \\
\text { characteristics }\end{array}$ & TARGIT-IORT & EBRT \\
\hline Number of patients (\% of total) & $60(48 \%)$ & $66(52 \%)$ \\
\hline $\begin{array}{l}\text { Age (mean years }+/-S D \text { ) } \\
\text { Range }\end{array}$ & $\begin{array}{l}63(+/-8.2) \\
50-83\end{array}$ & $\begin{array}{l}62(+/-7.4) \\
50-80\end{array}$ \\
\hline $\begin{array}{l}\text { Randomised prepathology (before WLE) } \\
\text { Randomised postpathology (after WLE) }\end{array}$ & $\begin{array}{l}4(7 \%) \\
56(93 \%)\end{array}$ & $\begin{array}{l}14(21 \%) \\
52(79 \%)\end{array}$ \\
\hline $\begin{array}{l}\text { Baseline assessments prior to any } \\
\text { surgery N (\% of treatment group) }\end{array}$ & $2(3 \%)$ & $12(18 \%)$ \\
\hline $\begin{array}{l}\text { Baseline BMI (mean score } \mathrm{kg} / \mathrm{m}^{2} \\
+/-\mathrm{SD}) \\
\text { Baseline BMI Group }{ }^{a} \text { (\% pf treatment } \\
\text { group) }\end{array}$ & $29(+/-5.5)$ & $30(+/-5.9)$ \\
\hline 1 - Underweight $(<18.5)$ & $0 \%$ & $0 \%$ \\
\hline 2 - Normal (18.5-24.99) & $30 \%$ & $16 \%$ \\
\hline 3 - Overweight (25-29.99) & $30 \%$ & $50 \%$ \\
\hline 4 - Obese (30+) & $40 \%$ & $34 \%$ \\
\hline $\begin{array}{l}\text { Tumour Size (mm mean } \pm \text { SD) } \\
\text { Tumour Size Group, \% of treatment } \\
\text { group }\end{array}$ & $10(+/-4.2)$ & $11(+/-5.0)$ \\
\hline$<11(\mathrm{~mm})$ & $62 \%$ & $52 \%$ \\
\hline $11-20(\mathrm{~mm})$ & $38 \%$ & $46 \%$ \\
\hline$>21(\mathrm{~mm})^{b}$ & - & $1.5 \%$ \\
\hline \multicolumn{3}{|l|}{ Tumour Grade, $n$ (\% of treatment group) } \\
\hline 1 & $37(62 \%)$ & $38(57 \%)$ \\
\hline 2 & $23(38 \%)$ & $27(41 \%)$ \\
\hline $3^{b}$ & 0 & $1(1.5 \%)$ \\
\hline \multicolumn{3}{|l|}{ Tumour Type, $n$ (\% of treatment group) } \\
\hline $\begin{array}{l}\text { IDC } \\
\text { Mixed IDC/ILC }\end{array}$ & $\begin{array}{l}59(98 \%) \\
1(1.7 \%)\end{array}$ & $\begin{array}{l}64(97 \%) \\
2(3 \%)\end{array}$ \\
\hline \multicolumn{3}{|l|}{ Lesions, n (\% of treatment group) } \\
\hline 1 & $60(100 \%)$ & $65(98 \%)$ \\
\hline $2^{b}$ & 0 & $1(1.5 \%)$ \\
\hline $\begin{array}{l}\text { Extensive DCIS ( }>25 \% \text { of tumour } \\
+ \text { inside and out of tumour) } n \text { ( } \% \\
\text { of treatment group) }\end{array}$ & 0 & $4(6.3 \%)$ \\
\hline \multicolumn{3}{|l|}{$\begin{array}{l}\text { Hormone receptor status, } n \text { (\% of } \\
\text { treatment group) }\end{array}$} \\
\hline$E R+v e$ & $60(100 \%)$ & $64(97 \%)$ \\
\hline$P R+v e$ & $44(73 \%)$ & $52(79 \%)$ \\
\hline$E R$ and $P R-v e^{b}$ & 0 & $2(3 \%)$ \\
\hline $\begin{array}{l}\text { Positive Nodes }{ }^{b}, n \text { (\% of treatment } \\
\text { group) }\end{array}$ & 0 & $\begin{array}{l}1(1.5 \%)(1 \\
\text { node) }\end{array}$ \\
\hline $\begin{array}{l}\text { Largest Specimen Length (mean } \\
-m m+/-S D \text { ) }\end{array}$ & $89(+/-37.2)$ & $89(+/-38.4)$ \\
\hline Range & $25-205$ & $40-267$ \\
\hline \multicolumn{3}{|c|}{ Extent of Axillary Surgery, $n$ (\% of treatment group) } \\
\hline $\mathrm{Nil}$ & $3(5 \%)$ & $2(3 \%)$ \\
\hline SLNBX & $49(82 \%)$ & $55(83 \%)$ \\
\hline Clearance & $8(13 \%)$ & $9(14 \%)$ \\
\hline
\end{tabular}

Table 1 Baseline patient characteristics by treatment (Continued)

\begin{tabular}{|c|c|c|}
\hline $\begin{array}{l}\text { Patient, treatment and tumour } \\
\text { characteristics }\end{array}$ & TARGIT-IORT & EBRT \\
\hline \multicolumn{3}{|c|}{ Further Surgery Required, $n$ (\% of treatment group) } \\
\hline SLNBX & $2(3.3 \%)$ & $2(3 \%)$ \\
\hline Margins & $2(3.3 \%)$ & $7(11 \%)$ \\
\hline Revision of Scar & $2(3.3 \%)$ & 0 \\
\hline Radiotherapy Dose Range (Gy) & $16-33^{c}$ & $45-50.4$ \\
\hline Fractions (range) & 1 & $25(25-28)$ \\
\hline $\begin{array}{l}\text { Boost Given (20Gy in } 10 \text { fractions), } \\
n \text { (\% of treatment group) }\end{array}$ & N/A & $11(17 \%)$ \\
\hline $\begin{array}{l}\text { Supraclavicular Treatment, } n \text { (\% of } \\
\text { treatment group) }\end{array}$ & N/A & $1(1.5 \%)$ \\
\hline $\begin{array}{l}\text { Chemotherapy given }{ }^{b} \text { ( } n, \% \text { of } \\
\text { treatment } \\
\text { group) }\end{array}$ & 0 & $1(1.5 \%)$ \\
\hline \multicolumn{3}{|c|}{ Baseline Cosmesis Scores (\% Excellent-Good), mean ( \pm SD) } \\
\hline Patient Harris & $85(+/-0.36)$ & $82(+/-0.39)$ \\
\hline Nurse Harris & $93(+/-0.25)$ & $92(+/-0.27)$ \\
\hline Doctor Harrist & $87(+/-0.35)$ & $100(+/-0.0)$ \\
\hline BCCT.Core & $83(+/-0.38)$ & $90(0.31)$ \\
\hline
\end{tabular}

Abbreviations: WLE: Wide Local Excision; BMI: body mass index; DCIS: ductal carcinoma in situ; $E B R T=$ external beam radiation therapy; $E R$ : estrogen receptor; IDC: invasive ductal carcinoma; ILC: invasive lobular carcinoma; $P R$ : progesterone receptor; $S D$ : standard deviation; SLNBx: sentinel lymph node biopsy; TARGIT-IORT: targeted intraoperative radiation therapy

${ }^{\text {a }}$ See reference $28 ;{ }^{\text {b }}$ Factors relevant only to the prepathology stratification; 'Dose to surface of applicator; † Significantly different $(p=0.003)$

(prepathology) earlier in the study - prior to postpathology becoming the more common approach at the Australian study centres).

All cosmetic assessments used the Global Harris Scoring System (also known as the Harvard Scale) of Excellent, Good, Fair or Poor (Additional file 1: Table S1) [10, 18, 23, 24]. Responses were dichotomized into Excellent-Good (EG) or Fair-Poor (FP) categories in order to facilitate comparison with other published studies of cosmesis. The digital photographs were analyzed separately [8] utilizing the validated objective BCCT.core software [14-16, 25]. Scores are referred to in the subsequent text as doctor (Radiation Oncologist), nurse, patient and BCCT.core.

\section{Analysis and Interpretation}

Statistical significance was set at the level of $p<0.01$ to account for multiple comparisons [26, 27].

IBM-SPSS-V22 (SPSS Inc.,Chicago, IL) was used for: non-parametric analysis (Mann-Whitney U-Tests and $\mathrm{Chi}^{2}$ tests) of raw unadjusted data, two sample t-tests for change between baseline and Year- 5 scores, and interrater reliability analysis using the Kappa statistic to determine consistency among raters. Kappa scores were interpreted based on levels of agreement described by Landis and Koch; <0 Poor, 0.0-0.20 Slight, 0.21-0.40 
Fair, 0.41-0.60 Moderate, 0.61-0.80 Substantial, 0.811.00 Almost perfect [28]. Generalized estimating equations (GEE) with a variable covariance structure were used for the longitudinal dichotomized cosmesis endpoint scored by doctors and nurses using SAS-V9.3 (SAS Institute, Cary, NC).

\section{Results}

Of the 385 Western Australian patients randomized into the TARGIT-A trial, the first 152 consecutive patients were invited to participate in this sub-study (further recruitment ceased due to resource constraints). Six declined participation; a further 20 were excluded due to confounders which would render cosmesis data uninterpretable, including (1) received both TARGIT-IORT and EBRT $(n=9)$; $(2)$ received TARGIT-IORT during WLE $(n=1)$; (3) no radiotherapy given $(n=2)$; or (4) history of contralateral disease $(n=8)$. This left 126 evaluable participants, of whom 60 had TARGIT-IORT and 66 had EBRT (Fig. 1).

\section{Participants and Compliance}

Initial compliance was very good and nearly identical across both treatment groups for all four rating systems but decreased over time. Availability of BCCT.core data at Years 3 and 4 fell below $50 \%$ and there was no data available at Year-5 (Additional file 1: Table S2).

Baseline patient characteristics were not different between treatment groups (Table 1).

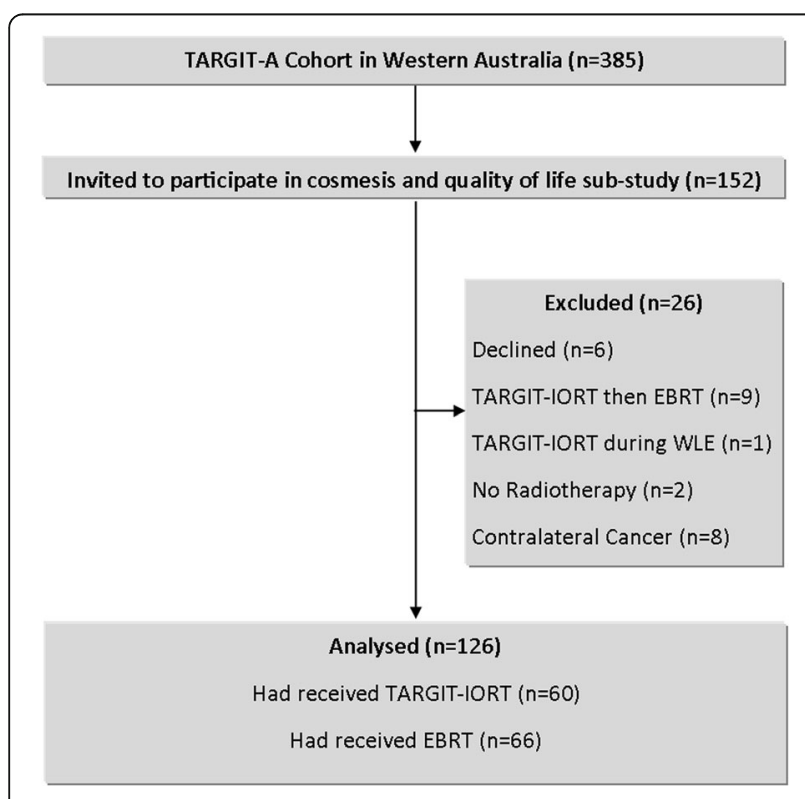

Fig. 1 CONSORT diagram

\section{Cosmesis}

At baseline, doctor scores for cosmesis were significantly better than results scored by patients in the EBRT group than the TARGIT-IORT group (100\% vs. $87 \%$ Fisher's Exact $p=0.003)$. Overall after treatment, a greater proportion of TARGIT-IORT patients scored an EG result compared to EBRT patients. Longitudinal multivariate analysis of cosmesis scores rated by doctors and nurses revealed no significant differences between patients treated with TARGIT-IORT and patients treated with EBRT (Additional file 1: Table S3). Un-dichotomized Harris Scale data are available in Additional file 1: Table S4.

Fisher's exact Chi-squared univariate analysis for each rating system revealed three significantly different time points; patient Year-5 scores were the most divergent, with $90 \%$ and $68.4 \%$ scoring an EG response for the TARGIT-IORT and EBRT groups respectively $(p=0.042)$ [9], followed by the Year-2 Nurse scores $(88.9 \%$ vs. $69.1 \%, p=0.018)$ and then baseline doctor scores of $86.5 \%$ and $100 \%$ respectively $(\mathrm{p}=0.003)$. Logistic regression with and without potential confounding variables (age, BMI, tumour size, tumour grade) did not alter these findings.

The proportion of EBRT patients achieving an EG outcome failed to return to the baseline proportion in the 45 years of follow-up across all rating systems however this was not statistically significant for any of the rating systems (Fig. 2). Patients who received EBRT also had a nonsignificant poorer outcome at Year- 5 when compared to baseline for all subjective rating systems ( $p=0.15$ patients; $p=0.11$ doctors; $p=0.05$, nurses).

To test whether additional factors, including age, time since treatment, body mass index (BMI) and specimen size may have an impact on cosmetic outcome scores, Generalized Estimating Equation Models were constructed including these factors. Time since treatment and BMI were found to be related to cosmetic outcome at some, but not all time points (Additional file 1: Table S3) [29]. In the model examining nurse scores, cosmesis outcomes in Years 1,2 and 3 were scored significantly worse than baseline $(p=0.004)$ for both treatment groups. Similarly, the model examining doctor scores found Year 1, 3 and 5 cosmetic outcome to be worse than baseline for both treatments $(p=0.018)$. Also in the doctor model, it was found that as patient BMI increased, the likelihood of scoring an EG result decreased (Estimate $-0.8, p=0.009$ ).

\section{Review of agreement between cosmesis rating systems}

Inter-rater reliability analysis revealed only 5 statistically significant Kappa scores out of the 36 observed time point pairings (Table 2). Four of these showed only fair agreement between raters. Only one time point scored moderate agreement which was between nurse and 
Patient
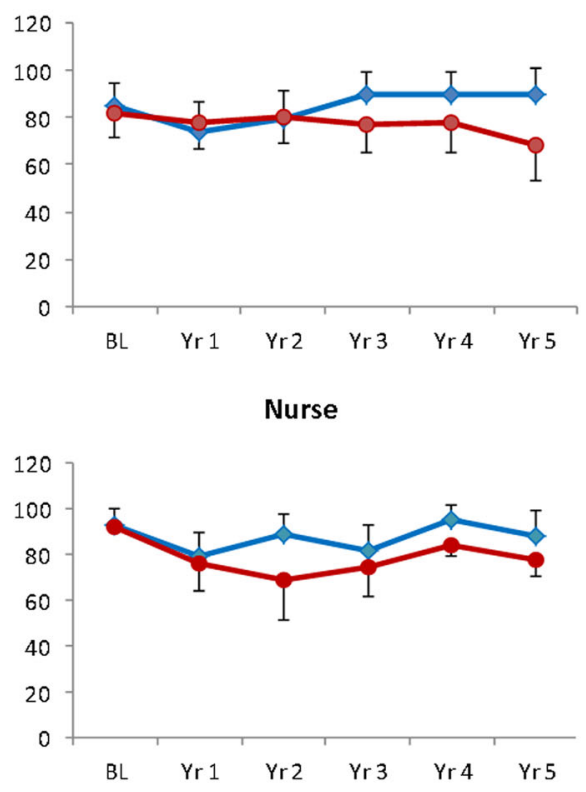

Doctor
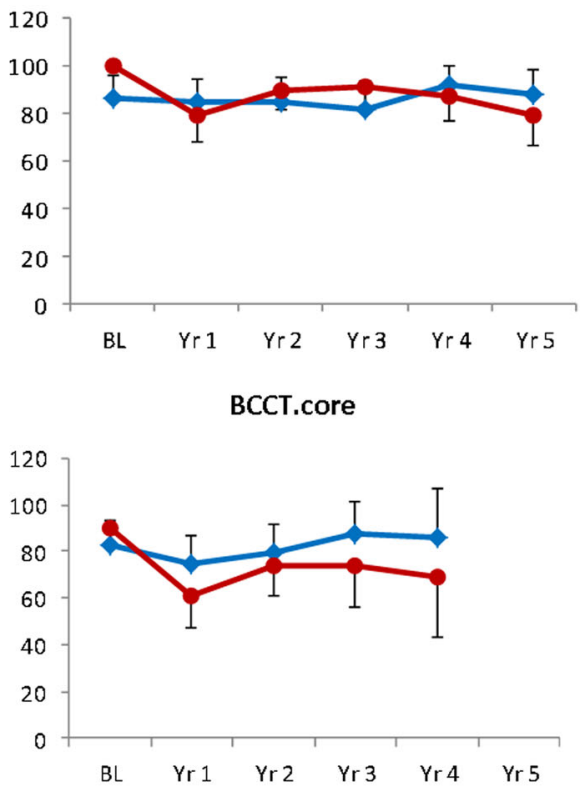

EBRT

The 95\% Confidence Intervals displayed are restricted to the upper limit for the TARGIT-IORT group and the lower limit for the EBRT group for viewing clarity only.

Fig. 2 Cosmesis Outcomes (\% Excellent-Good) by Rater. 95\% Confidence Intervals displayed are the upper limits for the TARGIT-IORT group and the lower limits for the EBRT group

doctor scores at Year 1 with Kappa $=0.46(p<0.001)$, 95\% CI $(0.24,0.68)$.

One can see that most of the variation in responses was in the EBRT arm. BCCT.core correlated well with patient scores in the TARGIT-IORT group but not in the EBRT group (Fig. 3).

Figure 3 illustrates that each rating system followed a similar trend, with overall cosmesis scores showing 25\% variation between raters within each of the 5 time points. Rater disagreement was seen such that doctors gave the most positive scores, followed by nurses, then patients and then BCCT.core. The significantly different time points $(p<0.01)$ between raters were Year 1 (doctors and BCCT.core both gave worse scores than nurses; doctors and nurses scored cosmesis better than patients) and Year 2 (BCCT.core gave worse scores than nurses) (Table 3).

In terms of percentage agreement, nurse and doctor scores appeared to be the most closely related with an overall agreement of $80.8 \%$; range $73.5 \%$ (Year 2) to $88.3 \%$ (baseline) (Table 2). The rating system that appeared most similar to the patient scores overall was the doctor scores, with an overall agreement of $78.6 \%$; range $73.2 \%$ at Year 3 to $80.8 \%$ at baseline).

\section{Sensitivity Analysis}

The effect of missing data on the patient scores at Year5 was tested by substituting the previous years' result. For the EBRT group, this increased the proportion of an EG score from $68.4 \%$ to $69 \%$ and for the TARGIT-IORT group it decreased the proportion from $90 \%$ to $88 \%$.

\section{Discussion of results}

Since its first use in 1998, intraoperative radiotherapy has been tested in randomised clinical trials and offered as adjuvant breast radiotherapy for over 20,000 women. Given the fact that breast cancer local recurrence outcomes are no different with TARGIT-IORT compared with EBRT, the obvious difference in patient experience (a single treatment instead of several weeks of daily treatments in the hospital) is of great importance.

Cosmetic outcome post various forms of intra-operative radiotherapy has been previously reported [8, 9, 30-34] however no study has compared four different rating systems, even with other approaches of breast conserving therapy. The earliest cosmetic assessment of TARGITIORT utilised a satisfaction index by asking patients to give a score for what she expected (E) and another for what she observed $(\mathrm{O})$. It was found that for appearance, 


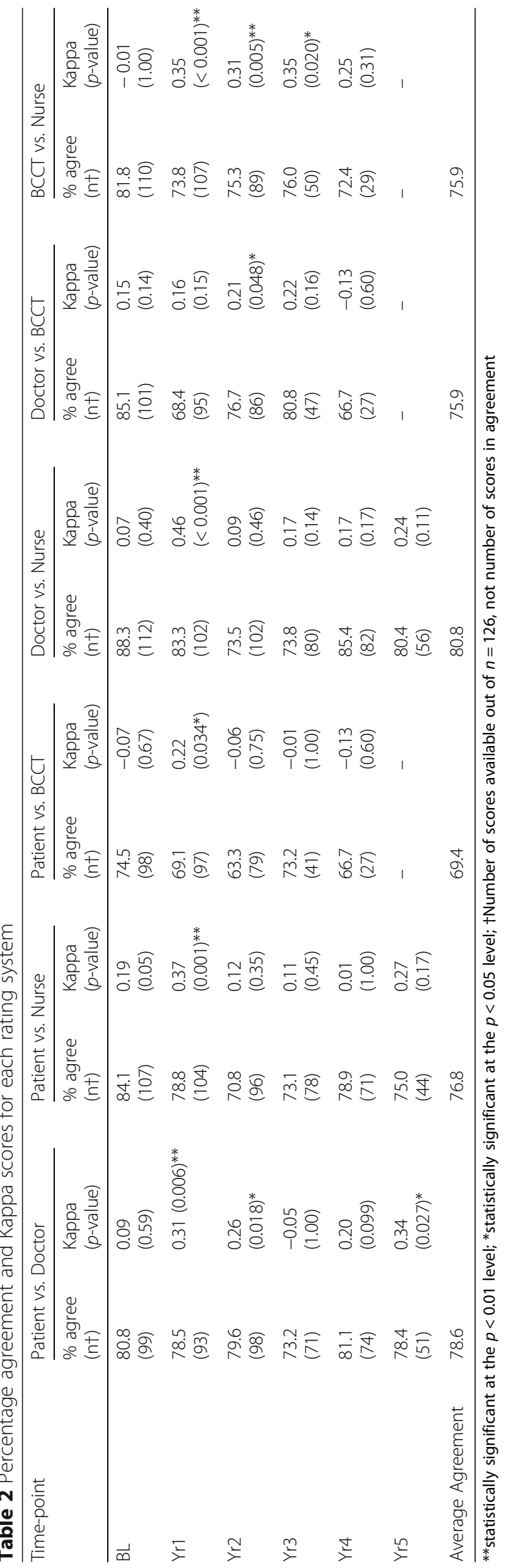




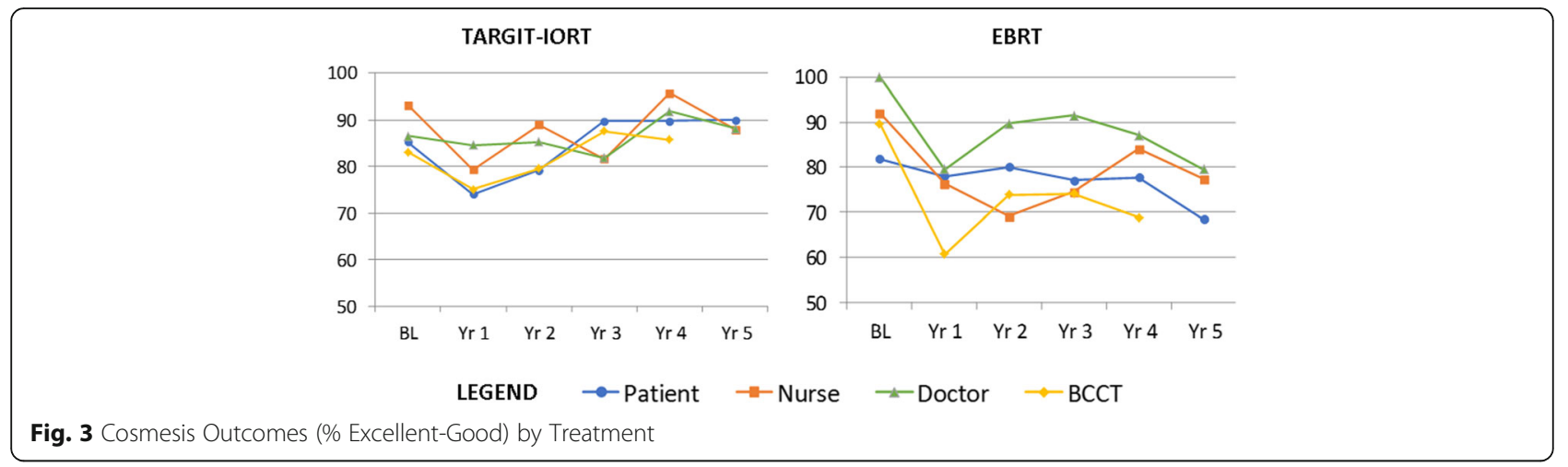

there was a trend for better scores for TARGIT IORT boost compared with EBRT and no difference between the two treatments was found for the satisfaction indices for texture $[35,36]$. The current TARGIT-A sub-study assessed the agreement in cosmetic outcome between one objective and three subjective rating systems, by investigating the proportion of patients scoring an ExcellentGood (EG) outcome in each treatment group. Overall, the majority of patients in both treatment groups scored an EG cosmetic result across all scoring systems, however $32 \%(12 / 38)$ of EBRT patients assessed at Year-5 selfreported a Fair-Poor result. This compares poorly to the 90\% of TARGIT-IORT patients (27/30 patients) selfreporting an EG result at this time-point, but nearly fits within the previously reported expectation that overall, $70-80 \%$ of EBRT patients will have an EG result [37]. Of those not providing a score at Year-5 due to having withdrawn $(n=3)$ or non-compliance $(n=11), 5$ out of 7 from the EBRT group had a previous EG score and 3 out of 4 from the TARGIT-IORT group had a previous EG score, suggesting that had they provided a 5 year score which maintained their previous score, the proportions may have

Table 3 Inter-rater Reliability - Significant Kappa Scores

\begin{tabular}{|c|c|c|c|}
\hline Time point & Rater Comparison (\% EG) & Kappa & $p$-value \\
\hline 1 Year & Patient (76) vs. Doctor^ (82) & $0.312^{* *}$ & $0.006 \# \#$ \\
\hline 1 Year & Patient (76) vs. Nurse (78)^ & $0.366^{* *}$ & $0.001 \# \#$ \\
\hline 1 Year & Patient (76)^ vs. BCCT (68) & $0.222^{* *}$ & $0.034 \#$ \\
\hline 1 Year & Nurse (78) vs. Doctor (82)^ & $0.461^{* * *}$ & $<0.001$ \#\# \\
\hline 1 Year & Nurse (78)^ vs. BCCT (68) & $0.345^{* *}$ & $<0.001 \# \#$ \\
\hline 2 Year & Patient (80) vs. Doctor (87)^ & $0.258^{* *}$ & $0.018 \#$ \\
\hline 2 Year & Doctor $(87) \wedge$ vs. BCCT (77) & $0.211^{* *}$ & $0.048 \#$ \\
\hline 2 Year & Nurse (79)^ vs. BCCT (77) & $0.314^{* *}$ & $0.005 \# \#$ \\
\hline 3 Year & Nurse (78) vs. BCCT (81)^ & $0.348^{* *}$ & $0.020 \#$ \\
\hline 5 Year & Patient (79) vs. Doctor (84)^ & $0.258^{* *}$ & $0.027 \#$ \\
\hline
\end{tabular}

**Fair agreement ${ }^{* * *}$ Moderate agreement \#\# $p<0.01 \#<0.05 \wedge$ scored higher proportion as EG been $69 \%$ and $88 \%$ respectively. This suggests study attrition did not cause the large difference at this time point. Further discussion about the patient-reported findings has been detailed elsewhere [9].

It is well known that EBRT can have a negative impact on long term cosmetic outcome. This was confirmed in this study, with the EBRT group failing to reach baseline proportions of EG scores across all follow-up time points and all rating systems. Although follow-up scores when compared to baseline scores were not statistically significantly different between the TARGIT-IORT and EBRT groups in the subjective measurements, TARGITIORT patients did reach baseline proportions of EG scores in all rating systems, from Year-3 or 4 onwards. This suggests IORT patients do experience an initial decline in cosmesis but this improves beyond the second year of follow-up. Baseline assessments were taken prior to surgery in 1 patient in the EBRT arm (2\%) and 12 patients (18\%) in the TARGIT-IORT arm, which may introduce some bias in the interpretation of these results. Previously reported BCCT.core data showed patients receiving TARGIT-IORT were significantly more likely to have an EG result at Year 1 and Year 2, compared to patients who received EBRT [8]. The only time point to have moderate agreement between two raters was Year-1, between nurses and doctors, when cosmesis scores were poorer than at other time points. This suggests that for both treatment groups, cosmetic outcome assessed by all raters reached a nadir at Year-1.

Overall, a higher proportion of patients in the present study had an EG result compared to other different modalities of intraoperative radiotherapy. The Montpellier study (IORT delivered via a linear accelerator) reported 'Excellent to Good' cosmetic scores at 6 months and a Mammosite study (utilizing a balloon applicator) found 84\% and 78\% Excellent to Good scores at Years 1 and 2 respectively [30,31]. Cosmetic assessments for these two studies were made by a clinician from physical assessments and photographic review and were not patient reported. Cosmetic outcome data from the ELIOT study 
(using 21Gy electron intra-operative radiotherapy) was reported as 'good' in the majority of cases, scored by both patients and clinicians [32]. A South African study delivering Iridium ${ }^{192}$ via after-loader found that $74 \%$ of patients reported an EG score after 7 years of follow-up [33].

Historically, patients have been known to evaluate cosmetic outcome more favourably than their clinicians, possibly due to a range of psychological factors; not wanting to displease their clinicians (or their teams) is a common suggestion. It may also be that factors other than aesthetics influence a patient's evaluation of cosmetic outcomes; it may be related to quality of life, expectations or the difference in interpretation of what the Harris Scale means between different raters $[20,38,39]$. In this study, we found that patients' self-assessments were similar to the objective assessment of the BCCT.core software, but only in those who received TARGIT-IORT, perhaps influenced by the better breast related quality of life with TARGIT-IORT [9]. Previous studies utilizing BCCT.core [17, 38, 39] have found that patients receiving EBRT score better than BCCT software. In this study, doctors were most likely to report an Excellent or Good outcome, followed by nurses. These results confirm previous research that subjective Harris Scale scores reported by the patient, her doctor and a nurse should not be used interchangeably $[12,13,17]$.

Guidelines produced by the EORTC in 2006 stated that since there was no 'gold standard', at least 3 measures should be used to assess cosmetic outcome: a subjective panel of 5 members using the Harris Scale; some form of objective measurement system; and some form of skin damage grading, however this may not always be practical $[17,40]$.

Some authors have stated that, as patients have to live with the outcome of treatment, the patient selfassessments are the most important; although some contest that due to the low reproducibility of such results and the high dependence on psycho-social factors, they should be measured in conjunction with an objective measurement system $(13,17,19,34)$. An approach used in the past has been blinded review by two or more radiation oncologists, however the BCCT.core system was used instead of blinded review in the present study. Even though BCCT software is an objective assessment, we posit that the most practical and perhaps most relevant measurements are those carried out by the patient herself. This is particularly true when it is used within the context of a randomised trial, as all other factors would be equally balanced between the two arms and any effect would be attributable to the randomised allocation and should reflect the real-world scenario. It would be ideal to use all four methods in every study, or a combination of at least two, but as the other methods are more resource intensive and if they don't correlate with the patient perception, they are arguably less relevant.

\section{Limitations and Strengths}

During the design of the present study there was no standardised approach for measuring cosmesis post breast conserving surgery in randomised controlled trials [40]. At the time, a combination of several measures was considered better than one, hence four available and practical measures were undertaken (patient, doctor, nurse, and digital photographs in accordance with the Christie protocol $[12,22])$. It was not until later that the BCCT.core software became available and subsequently applied to the photographs as a more contemporary computerised assessment technology than the originally planned Christie approach [8]. This study had excellent compliance rates for patient, nurse and doctor scores; however, digital photographs were not available for many patients towards the end of the study, which resulted in missing data for the objective cosmesis measurements. The impracticalities of annual photography contributed to the restriction of this sub-study to the first $152 \mathrm{pa}-$ tients registered in Western Australia [17] and reduced compliance in the later years, with the large geographical dispersion of patients in Western Australia potentially influencing return to the study centre. Image quality was also an issue, with some photographs not meeting the requirements for assessment by BCCT.core. The proportion of available BCCT.core data at Year 3 and Year 4 was only $44 \%$ and $27 \%$ respectively, hence the later BCCT results should be considered with caution. With current and future technology, and the awareness of the BCCT.core software, image quality should not be a problem for future prospective trials.

Doctor and nurse scores were not formally blinded to treatment received which may be a potential source of bias. Despite using a standard protocol, the doctor and nurse scores may also attract intra-rater bias as different doctors and nurses may have completed the cosmesis Harris scores. It was impractical to have the same assessors or photographers at each visit for the long duration of the study; however it was always the same patient assessing herself each time. This consistency is yet another argument to rely more on the patient's own assessment than any other.

Another limitation is that there may be cultural differences in attitude to cosmetic outcome that may reduce the generalisability of the inter-rater results to different populations.

\section{Conclusion}

As found in previous studies, a numerically higher proportion of patients treated with TARGIT-IORT had an Excellent-Good outcome compared with those who received EBRT. In this study, we found that there was little agreement between the four cosmetic rating systems used; in particular, patients' score did not always correlate with 
the scores by doctors, nurses or the BCCT.core software. While on one hand, the objective assessment of cosmetic outcome used along with subjective assessments by staff and patients may be the ideal way to assess cosmesis, it can be argued that patient opinion of cosmetic outcome is the most important and may be the only outcome measured, particularly when resources are limited. In a randomised trial, the patient's own assessment would give the most realistic measure of the difference in the cosmetic impacts of compared treatments.

\section{Additional file}

Additional file 1: Supplementary Tables. (PDF 309 kb)

\section{Abbreviations}

BAT: Breast Analysing Tool; BCCT.core: Breast Cancer Conservative Treatment, cosmetic results (software); BRA: Breast Retraction Assessment; Cl: Confidence Interval; EBRT: External Beam Radiotherapy (whole breast); EG: Excellent-Good (cosmetic outcome); FP: Fair-Poor (cosmetic outcome); Gy: Gray (unit of measurement of radiation); IBM-SPSS: Statistical Package for the Social Sciences (software); IORT: Intraoperative RadioTherapy; ISRCTN: International Standard Randomised Controlled Trial Number; SAS: Statistical Analysis System (software); TARGIT-A: Targeted intraoperative radiotherapy versus whole breast radiotherapy for breast cancer: an international randomised clinical trial; TARGIT-IORT: risk-adapted single-dose intra-operative radiotherapy utilizing the Intrabeam device; WLE: wide local excision

\section{Acknowledgments}

The investigators would like to thank all of the TARGIT-A Trial Sub-Study participants, as well as local clinicians and research coordinators for their long term and ongoing involvement in the study. Further acknowledgement is also required for the support of the TARGIT-A Steering Committee and Coordinating Centres.

\section{Funding}

This work has been supported in Australia by a National Health and Medical Research Council Project Grant (393703), a Cancer and Palliative Care Research and Evaluation Unit Small Project Early Investigator Grant (SG12/ 001) and a Cancer Council of Western Australia Project Grant (APP1021376). The TARGIT-A trial was supported by the HTA programme of National Institute of Health Research, UK.

\section{Availability of data and materials}

All data generated or analyzed during this study are available from the corresponding author on reasonable request.

\section{Authors' contributions}

Conception and design: DJ, TC, and CS. Provision of study materials or patients: DJ, CS, and MT. Collection and assembly of data: TC, DJ, MT, CS, NW, JSV and MK. Data analysis and interpretation: All authors. Manuscript writing: All authors. All authors read and approved the final manuscript.

\section{Ethics approval and consent to participate}

This research was conducted as a sub-study of the TARGIT-A Trial (ISRCTN $34,086,741)$. Ethical and institutional approval was granted to all participating sites prior to commencement of patient recruitment (Lead Ethics Committee: Sir Charles Gairdner Hospital, Reference 2003-108). Patients were required to provide written informed consent to participate in this research.

\section{Consent for publication}

Not Applicable

\section{Competing Interests}

DJ received a research grant from Photoelectron Corp in 2001 to support data management. JSV received a research grant from Photoelectron Corp
(1996-99) and from Carl Zeiss for supporting data management at the University of Dundee (Dundee, UK) and has subsequently received honoraria. $\mathrm{MB}$ was on the scientific advisory board of Carl Zeiss and was paid monthly consultancy fees until 2010. Carl Zeiss sponsored some of the travel and accommodation for meetings of the international steering committee and when necessary for conferences where a presentation about targeted intraoperative radiotherapy is being made for all authors apart from AN and MT. Carl Zeiss had no involvement in this publication.

\section{Publisher's Note}

Springer Nature remains neutral with regard to jurisdictional claims in published maps and institutional affiliations.

\section{Author details}

${ }^{1}$ Radiation Oncology Clinical Trials and Research Unit, Comprehensive Cancer Centre, Sir Charles Gairdner Hospital, Nedlands, WA 6009, Australia. ${ }^{2}$ Medical School, University of Western Australia, Nedlands, WA 6009, Australia. ${ }^{3}$ Institute for Health Research, University of Notre Dame, 19 Mouat Street, Fremantle, WA 6160, Australia. ${ }^{4}$ Radiation Oncology, Comprehensive Cancer Centre, Sir Charles Gairdner Hospital, Nedlands, WA 6009, Australia. ${ }^{5}$ Surgical \& Interventional Trials Unit, Division of Surgery \& Interventional Science, Faculty of Medical Sciences, University College London, London NW1 2FD, UK. ${ }^{6}$ Royal Free London Foundation NHS Trust, Division of Surgical Sciences, The Breast Unit, Pond Street, Hampstead, London NW3 2QG, UK. ${ }^{7}$ Division of Surgery \& Interventional Science, University College London, London W1W 7TS, UK; Whittington Hospital, Royal Free Hospital and University College Hospital, University College London, London NW1 2FD, UK.

Received: 30 August 2017 Accepted: 13 March 2018

Published online: 13 April 2018

\section{References}

1. Fisher B, Bryant J, Dignam JJ, et al. Tamoxifen, radiation therapy, or both for prevention of ipsilateral breast tumor recurrence after lumpectomy in women with invasive breast cancers of one centimeter or less. J Clin Oncol. 2002:20(20):4141-9.

2. Liljegren G, Holmberg L, Adami HO, et al. Sector Resection With or Without Postoperative Radiotherapy for Stage I Breast Cancer: Five-Year Results of a Randomized Trial. J Natl Cancer Inst. 1994;86(9):717-22.

3. Forrest AP, Stewart HJ, Everington D, et al. Randomised controlled trial of conservation therapy for breast cancer: 6-year analysis of the Scottish trial. Lancet. 1996;348(9029):708-13.

4. Veronesi U, Marubini E, Mariani L, et al. Radiotherapy after breast-conserving surgery in small breast carcinoma: Long-term results of a randomized trial. Ann Oncol. 2001:12(7):997-1003.

5. Early Breast Cancer Trialists' Collaborative Group. Effects of radiotherapy and of differences in the extent of surgery for early breast cancer on local recurrence and 15-year survival: an overview of the randomised trials. Lancet. 2005;366(9503):2087-106.

6. Smith BD, Bentzen SM, Correa CR, et al. Fractionation for Whole Breast Irradiation: An American Society for Radiation Oncology (ASTRO) EvidenceBased Guideline. Int J Radiat Oncol Biol Phys. 2011;81(1):59-68.

7. Vaidya JS, Wenz F, Bulsara M, et al. Risk-adapted targeted intraoperative radiotherapy versus whole-breast radiotherapy for breast cancer: 5-year results for local control and overall survival from the TARGIT-A randomised trial. Lancet. 2014;383(9917):603-13.

8. Keshtgar M, Williams N, Bulsara M, et al. Objective assessment of cosmetic outcome after targeted intraoperative radiotherapy in breast cancer: results from a randomised controlled trial. Breast Cancer Res Treat 2013;140(3):519-25.

9. Corica T, Nowak AK, Saunders CM, et al. Cosmesis and Breast-Related Quality of Life Outcomes After Intraoperative Radiation Therapy for Early Breast Cancer: A Substudy of the TARGIT-A Trial. Int J Radiat Oncol Biol Phys. 2016;96(1):55-64.

10. Harris JR, Levene MB, Svensson G, et al. Analysis of cosmetic results following primary radiation therapy for stages I and II carcinoma of the breast. Int J Radiat Oncol Biol Phys. 1979;5(2):257-61.

11. Pezner RD, Patterson MP, Hill LR, et al. Breast retraction assessment: an objective evaluation of cosmetic results of patients treated conservatively for breast cancer. Int J Radiat Oncol Biol Phys. 1985;11(3):575-8. 
12. Christie D, Sharpley C, Curtis T. Improving the accuracy of a photographic assessment system for breast cosmesis. Clin Oncol. 2005;17(1):27-31.

13. Fitzal $F$, Krois $W$, Trischler $H$, et al. The use of a breast symmetry index for objective evaluation of breast cosmesis. Breast. 2007;16(4):429-35.

14. Cardoso MJ, Cardoso J, Amaral N, et al. Turning subjective into objective: The BCCT.core software for evaluation of cosmetic results in breast cancer conservative treatment. Breast. 2007;16(5):456-61.

15. Cardoso M, Magalhães A, Almeida T, et al. Is face-only photographic view enough for the aesthetic evaluation of breast cancer conservative treatment? Breast Cancer Res Treat. 2008;112(3):565-8.

16. Cardoso M, Cardoso J, Wild T, et al. Comparing two objective methods for the aesthetic evaluation of breast cancer conservative treatment. Breast Cancer Res Treat. 2009;116(1):149-52.

17. Cardoso MJ, Cardoso JS, Oliveira HP, et al. The breast cancer conservative treatment. Cosmetic results - BCCT.core - Software for objective assessment of esthetic outcome in breast cancer conservative treatment: A narrative review. Comput Methods Prog Biomed. 2016:126:154-9.

18. Cardoso MJ, Cardoso J, Santos AC, et al. Interobserver agreement and consensus over the esthetic evaluation of conservative treatment for breast cancer. Breast. 2006;15(1):52-7.

19. Al-Ghazal SK, Blamey RW. Cosmetic assessment of breast-conserving surgery for primary breast cancer. Breast. 1999;8(4):162-8.

20. Sneeuw KCA, Aaronson NK, Yarnold JR, et al. Cosmetic and functional outcomes of breast conserving treatment for early stage breast cancer. 1 . Comparison of patients' ratings, observers' ratings and objective assessments. Radiother Oncol. 1992;25(3):153-9.

21. Vaidya JS, Joseph DJ, Tobias JS, et al. Targeted intraoperative radiotherapy versus whole breast radiotherapy for breast cancer (TARGIT-A trial): an international, prospective, randomised, non-inferiority phase 3 trial. Lancet. 2010;376(9735):91-102.

22. Christie DRH, O'Brien MY, Christie JA, et al. A comparison of methods of cosmetic assessment in breast conservation treatment. The Breast. 1996;5(5): 358-67.

23. Kramer BA, Arthur DW, Ulin K, et al. Cosmetic Outcome in Patients Receiving an Interstitial Implant as Part of Breast-Conservation Therapy1. Radiology. 1999;213(1):61-6.

24. Rose MA, Olivotto I, Cady B, et al. Conservative surgery and radiation therapy for early breast cancer. Long-term cosmetic results. Arch Surg. 1989; 124(2):153-7.

25. Cardoso JS, Cardoso MJ. Towards an intelligent medical system for the aesthetic evaluation of breast cancer conservative treatment. Artif Intell Med. 2007:40(2):115-26.

26. Bland JM, Altman DG. Multiple significance tests: the Bonferroni method. BMJ. 1995;310(6973):170.

27. Bottomley A, Biganzoli L, Cufer T, et al. Randomized, Controlled Trial Investigating Short-Term Health-Related Quality of Life With Doxorubicin and Paclitaxel Versus Doxorubicin and Cyclophosphamide As First-Line Chemotherapy in Patients With Metastatic Breast Cancer: European Organization for Research and Treatment of Cancer Breast Cancer Group, Investigational Drug Branch for Breast Cancer and the New Drug Development Group Study. J Clin Oncol. 2004:22(13):2576-86.

28. Landis JR, Koch, G. G. The measurement of observer agreement for categorical data. Biometrics 1977 33:159-174,

29. Australian Government Department of Health. About Overweight and Obesity. Canberra: Australian Government Department of Health; 2009.

30. Lemanski C, Azria D, Gourgon-Bourgade S, et al. Intraoperative Radiotherapy in Early-Stage Breast Cancer: Results of the Montpellier Phase II Trial. Int J Radiat Oncol Biol Phys. 2010;76(3):698-703.

31. Belkacémi Y, Chauvet M-P, Giard S, et al. Partial breast irradiation as sole therapy for low risk breast carcinoma: Early toxicity, cosmesis and quality of life results of a MammoSite brachytherapy phase II study. Radiother Oncol. 2009;90(1):23-9.

32. Veronesi $U$, Orecchia $R$, Luini $A$, et al. Full-dose intra-operative radiotherapy with electrons (ELIOT) during breast-conserving surgery: experience with 1246 cases. Ecancermedicalscience [Internet]. 2008; 2. Available from: https://www.ncbi.nlm.nih.gov/pmc/articles/PMC3234040/pdf/can-2-65.pdf.

33. Baatjes KJ, Apffelstaedt JP. 7-year follow up of intra-operative radiotherapy for early breast cancer in a developing country. Breast. 2012;21(3):326-9.

34. Cracco S, Semprini G, Cattin F, et al. Impact of Intraoperative Radiotherapy on Cosmetic Outcome and Complications after Oncoplastic Breast Surgery. Breast J. 2015;21(3):285-90.
35. Vaidya JS. A novel approach for the local treatment of breast cancer: College of London; 2002. Available from: http://www.ucl.ac.uk/ rmhkjsv/ papers/thesis.pdf.

36. Vaidya J, Wilson A, Houghton J, et al. Cosmetic outcome after targeted intraoperative radiotherapy (targit) for early breast cancer. Breast Cancer Res Treat 82(S180), 2003. Available from: https://goo.gl/Cw5AxG.

37. Buchholz TA. Radiation Therapy for Early-Stage Breast Cancer after BreastConserving Surgery. N Engl J Med. 2009;360(1):63-70.

38. Heil J, Dahlkamp J, Golatta M, et al. Aesthetics in Breast Conserving Therapy: Do Objectively Measured Results Match Patients' Evaluations? Ann Surg Oncol. 2011:18(1):134-8.

39. Hau E, Browne L, Khanna S, et al. Radiotherapy Breast Boost With Reduced Whole-Breast Dose Is Associated With Improved Cosmesis: The Results of a Comprehensive Assessment From the St. George and Wollongong Randomized Breast Boost Trial. Int J Radiat Oncol Biol Phys. 2012;82(2):682-9.

40. Cardoso M, Cardoso J, Vrieling C, et al. Recommendations for the aesthetic evaluation of breast cancer conservative treatment. Breast Cancer Res Treat. 2012;135(3):629-37.

\section{Submit your next manuscript to BioMed Central and we will help you at every step:}

- We accept pre-submission inquiries

- Our selector tool helps you to find the most relevant journal

- We provide round the clock customer support

- Convenient online submission

- Thorough peer review

- Inclusion in PubMed and all major indexing services

- Maximum visibility for your research

Submit your manuscript at www.biomedcentral.com/submit
) Biomed Central 